\title{
IDENTIFICATION OF CROSS-REACTIVE CARBOHYDRATE DETERMINANTS IN SUBJECTS REPORTING WORK-RELATED RESPIRATORY SYMPTOMS
}

\section{MARTA WISZNIEWSKA ${ }^{1}$, JOANNA ZGORZELSKA-KOWALIK ${ }^{1}$, EWA NOWAKOWSKA-ŚWIRTA², and JOLANTA WALUSIAK-SKORUPA ${ }^{1}$}

${ }^{1}$ Nofer Institute of Occupational Medicine, Łódź, Poland

Department of Occupational Diseases

${ }^{2}$ Nofer Institute of Occupational Medicine, Łódź, Poland

Laboratory of Allergic Diagnostics and Occupational Diseases

\begin{abstract}
Objectives: The role of cross-reactive carbohydrate determinants (CCDs) in diagnostics of occupational allergy remains unclarified and its clinical relevance is still questioned. The aim of the study was to assess the frequency of positive response to CCDs in the subjects with suspected occupational allergy and the relationship between other diagnostic test results and final diagnosis. Material and Methods: The study group included 201 patients. They underwent clinical examination, skin prick test (SPT) to common and occupational allergens, specific serum immunoglobulin (sIgE) determinations, spirometry and specific inhalation challenge test. Moreover, sIgE to CCDs from bromelain was assessed in all subjects. Results: Occupational respiratory allergy was recognized in $64.3 \%$ of CCD-positive and $52.4 \%$ of CCD-negative patients. Positive SPT results to common and occupational allergens were found in $64.3 \%$ and $35.7 \%$ of CCD-positive subjects, respectively. In all subjects with CCDs, the sIgE to grass pollens as well as to occupational allergens were detected. The total IgE level $>100 \mathrm{kU} / \mathrm{l}$ was significantly associated with the presence of sIgE to CCDs. Conclusions: SIgE to CCDs were found in $7 \%$ of subjects suspected to suffer from occupational respiratory allergy. The presence of CCDs is not significantly associated with occupational respiratory allergy. It is also not more frequent in subjects reporting work-related respiratory symptoms in whom occupational allergy was not confirmed. The elevated total IgE level was related with CCD positivity. In patients with suspected occupational allergy, the presence of sIgE to CCDs in serum did not indicate the irrelevance of positive sIgE to occupational allergens.
\end{abstract}

Key words:

Occupational allergy, Cross-reactive carbohydrate determinants, CCDs, Work-related respiratory symptoms

Funding: The study was conducted in 2008 and 2010 as part of the realization of the Nofer Institute of Occupational Medicine project IMP 12.3 entitled "Standardization of diagnostic methods in IgE-mediated occupational allergy", financed with the resources granted by the Ministry of Science and Higher Education. Project leader: Marta Wiszniewska, MD, PhD.

Received: March 11, 2014. Accepted: August 19, 2014.

Corresponding author: M. Wiszniewska, Nofer Institute of Occupational Medicine, Department of Occupational Diseases, św. Teresy 8, 91-348 Łódź, Poland (e-mail: martaz@imp.lodz.pl). 


\section{INTRODUCTION}

The interpretation of results obtained by specific immunoglobulin $\mathrm{E}$ ( $\mathrm{SIgE}$ ) testing requires a cautious and sensible approach. Positive results most often indicate IgE-mediated sensitization; however, the clinical relevance is likely only in the context of clinical symptoms, since the false-negative and false-positive results can happen [1,2]. It is emphasized that the immunologic response may only reflect exposure and/or the immunologic nature of the tested allergen. It may have also resulted from the presence of $\mathrm{IgE}$ directed against carbohydrate determinants.

In the early 1980s, Aalberse et al. described the presence of IgE directed against the cross-reactive carbohydrate determinants (CCDs) in patients sera [3,4]. The cross-reactive carbohydrate determinants may cause production of anti-CCD IgE and many allergic patients develop specific serum immunoglobulin $\mathrm{E}$ (sIgE) directed against plant and/or insect protein-linked glycans [5]. It has been postulated that the presence of anti-CCD IgE is not clinically relevant, especially when it is related to negative reactions to skin tests and lack of clinical symptoms [6,7].

We have recently reported the preliminary results related to the presence of CCDs in 81 patients suspected to be affected by occupational allergy. The initial results indicated that SIgE to CCDs could be found in about $10 \%$ subjects and detection of CCDs in serum was not helpful in diagnostics of occupational allergy [8]. Since data on the anti-CCD IgE prevalence in a large cohort of subjects with allergy symptoms due to workplace exposure are limited and the role of CCDs in diagnostics of occupational allergy remains unclarified, the authors have decided to expand the study group.

The aim of the present study was to evaluate the frequency of positive response to CCDs in the subjects with suspected occupational allergy and its relation to the results of other diagnostic tests and final diagnosis.

\section{MATERIAL AND METHODS}

The study group included 201 patients (bakers, farmers, healthcare workers (HCWs), carpenters and single other occupations, i.e., veterinarian, poultry farm worker, cleaner, seamstress, ceramics decorator, leather cutter, pharmacist) suspected to be affected by occupational respiratory allergy (asthma and/or rhinitis), diagnosed at our Department of Occupational Diseases between 2008 and 2010. After completion of the diagnostic procedures, the study group was divided taking into account the final diagnosis (subjects with occupational respiratory allergy vs. suspected occupational allergy) and anti-CCD IgE determination results (CCD-positive vs. CCD-negative subjects) to compare statistically the various parameters.

The subjects were administered a questionnaire that included e.g., a history of respiratory symptoms (rhinitis, itching, nasal blockage, cough, wheezing, shortness of breath, chest tightness), skin symptoms, personal and family history of atopy, exposure to pet allergens at home, medication use, and smoking habits.

Skin prick tests (SPT) were performed on the volar part of the forearm with a standard battery of common allergens including tree and grass pollens, Dermatophagoides pteronyssinus, Dermatophagoides farinae, moulds, weeds (Allergopharma, Reinbek, Germany) and with occupational allergens depending on patient's profession: bakery series ( $\alpha$-amylase, oatmeal, wheat, corn, barley and rye flour), farmers occupational allergens (mixture of grain, hay, horse epithelium, swine epithelium, sheep, goat, rabbit epithelium, fur, barley, corn, oat, rye, wheat, cereals, straw); HCW allergens (latex, chloramine, formaldehyde, glutaraldehyde, chlorhexidine, benzalkonium chloride solutions), wood dust series (spruce, oak, pine, fir and beech wood) (Allergopharma, Germany; Stallergens, France). Allergen diluents were used as the negative control, while $1 \mathrm{mg} / \mathrm{ml}$ histamine dihydrochloride solution was the positive one. The largest wheal diameter 
was assessed after $15 \mathrm{~min}$. A weal diameter of $3 \mathrm{~mm}$ or more and equal to or greater than half of that formed by histamine was defined as positive, hence indicating sensitization.

Depending on SPT results, patients were grouped as mono-sensitized, i.e., hyperreactive to an individual common allergen (dust mite, pollen, mould or feather allergen) or as multiple-sensitized, i.e., hyperreactive to 2, 3 or 4 different groups of common allergens.

Total serum IgE was evaluated using the ImmunoCap (Phadia, Sweden). Total IgE level $>100 \mathrm{kU} / \mathrm{l}$ was considered as elevated. Specific serum IgE against flours and $\alpha$-amylase were measured among bakers (fx20, k87 Phadia, Sweden), farmers were tested for grain, animal fur and/or bird feather allergens (e4, e83, ex71 Phadia, Sweden), mixed disinfectants and latex were examined in HCWs (pax6: chloramine, formaldehyde, glutaraldehyde, phthalic anhydride; k82 Phadia, Sweden), different kinds of wood were tested among carpenters (spruce-k35, fir-k44, oak-k33, pine-k36; Allergopharma, Germany). Among 15 subjects with other occupations, the sIgE were selected according to occupational exposure. The $\mathrm{sIgE}$ levels $\geq 0.35 \mathrm{kU} / 1$ were regarded as positive. Moreover, MUXF3 CCDs from bromelain were determined in all subjects (Ro214, Phadia, Sweden). Additionally, among CCD-positive patients (with presence of sIgE to CCDs from bromelain in serum) the horseradish peroxidase (HRP) and SIgE to grass pollens were measured (Ro400, gx1, Phadia, Sweden).

Specific inhalation challenge tests (SICT) with occupational allergens were performed in a work-site simulation setting (room space $6 \mathrm{~m}^{2}$ with temperature $22-25^{\circ} \mathrm{C}$ ) with the patient's own samples. The patient was sifting approximately $500 \mathrm{~g}$ of solid materials (e.g., flours and improvers, farmer's allergens, wood dusts) and for liquid substances the test was done by painting the solution onto a $2 \mathrm{~m}^{2}$ piece of cardboard in a challenge chamber for 30 min or until the asthmatic reaction symptoms appeared. Potato flour or lactose were used as placebo, the test was performed one day before SCIT.

The subjects who did not show significant $(\geq 20 \%)$ fall in forced expiratory volume in $1 \mathrm{~s}\left(\mathrm{FEV}_{1}\right)$ during the challenge test, underwent a repeated challenge test lasting $2 \mathrm{~h}$ on the next day. In patients with changes in $\mathrm{FEV}_{1}$ ranging between 10 and $20 \%$ after that challenge, the exposure was prolonged up to $3 \mathrm{~h}$.

The study participants did not receive any systemic or local medication. Inhaled short-acting $\beta_{2}$-agonists were stopped at least $8 \mathrm{~h}$ before the study, inhaled long-acting $\beta_{2}$-agonists $-48 \mathrm{~h}$, inhaled steroids -5 days, systemic steroids - 14 days. Antihistamine medications were stopped 7-42 days before challenge test, depending on the time for which the drugs were active.

Resting spirometry (Vicatest 2A, The Netherlands) was performed in all subjects. Bronchial response was measured by serial monitoring of $\mathrm{FEV}_{1}$ before and $5 \mathrm{~min}$, $30 \mathrm{~min}, 1 \mathrm{~h}, 2 \mathrm{~h}, 4 \mathrm{~h}, 6 \mathrm{~h}$ and $24 \mathrm{~h}$ after the provocation. The non-specific bronchial hyperreactivity (histamine challenge) was evaluated on the day before the SICT and $24 \mathrm{~h}$ after the test.

Occupational allergic rhinitis was recognized in subjects reporting work-related nasal symptoms with positive nasal response to provocation test, i.e., total score of more than 3 points and significant increase in total count and proportion of eosinophils (2-fold increase and eosinophilia at least $5 \%$ after challenge) in nasal lavage fluid. Recognition of occupational asthma was based on SICT with evaluation of bronchial response (at least a 20\% decrease in $\mathrm{FEV}_{1}$ ), or a 3-fold increase in non-specific bronchial hyperreactivity accompanied by increased sputum eosinophilia (at least $3 \%$ of eosinophils after the SICT). The group of patients with suspected occupational allergy included subjects reporting work-related respiratory symptoms, for whom the SICT did not induce significant bronchial response as well as subjects reporting work-related nasal symptoms with negative nasal response to SICT. 


\section{ETHICS}

The Regional Bioethical Committee approved the study protocol (approval decision number 15/2008). All of the participants gave their informed consent prior to the study.

\section{STATISTICS}

Statistical analyses were performed using Statistica 8. Continuous variables were expressed as mean values \pm standard deviations while the nominal variables were specified as numbers and percentages. Chi ${ }^{2}$ test (or Fisher's exact test) and Wilcoxon rank sum test were used to compare subjects with occupational respiratory allergy and patients with suspected occupational allergy as well as in the study population in relation to the presence of $\operatorname{sIgE}$ to CCDs in serum. A p-value $<0.05$ was considered as significant.

\section{RESULTS}

The group under the study consisted of 117 bakers, 35 farmers, $29 \mathrm{HCWs}$ and 20 subjects representing other occupations. Specific IgE to MUXF3 CCDs were found in 14 subjects (7\%), while the $\operatorname{sgE}$ to HRP was found among 13 CCD-positive patients. Occupational asthma and/or rhinitis were recognized in 9 (64.3\%) CCD-positive patients and 98 (52.4\%) subjects without sIgE to CCDs. The other 5 subjects with positive sIgE to CCDs were diagnosed with non-occupational respiratory disease. No occupational respiratory allergic disease was recognised amid $47.6 \%$ of patients without SIgE to CCDs in serum. Table 1 gives the characteristics of the study group.

The sIgE to grass pollens as well as to occupational allergens were detected in all subjects with anti-CCD

Table 1. Characteristics of patients and duration of reported symptoms in the study population

\begin{tabular}{|c|c|c|c|}
\hline Variable & $\begin{array}{c}\text { Total } \\
(\mathrm{N}=201) \\
\end{array}$ & $\begin{array}{c}\text { CCD-positive } \\
(\mathrm{N}=14)\end{array}$ & $\begin{array}{c}\text { CCD-negative } \\
(\mathrm{N}=187)\end{array}$ \\
\hline Age (years) [M $\pm \mathrm{SD}$ (min.-max)] & $40.3 \pm 10.8(20-61)$ & $38.6 \pm 8.6(23-53)$ & $40.5 \pm 10.9(20-61)$ \\
\hline \multicolumn{4}{|l|}{ Occupation $[\mathrm{n}(\%)]$} \\
\hline baker & $117(58.2)$ & $8(57.1)$ & $109(58.3)$ \\
\hline farmer & $35(17.4)$ & $4(28.6)$ & $31(16.6)$ \\
\hline health care worker & $29(14.4)$ & $1(7.1)$ & $28(15.0)$ \\
\hline carpenter & $5(2.5)$ & $1(7.1)$ & $4(2.1)$ \\
\hline other & $15(9.9)$ & 0 & $15(8.0)$ \\
\hline Occupational respiratory allergy disease $[\mathrm{n}(\%)]$ & $107(53.2)$ & $9(64.3)$ & $98(52.4)$ \\
\hline Occupational asthma [n (\%)] & $79(39.3)$ & $7(50.0)$ & $72(38.5)$ \\
\hline Occupational rhinitis $[\mathrm{n}(\%)]$ & $85(42.3)$ & $6(42.9)$ & $79(42.2)$ \\
\hline Occupational contact dermatitis [n $(\%)]$ & $26(12.9)$ & $2(14.3)$ & $24(12.8)$ \\
\hline Work-related respiratory symptoms $[\mathrm{n}(\%)]$ & $94(46.8)$ & $5(35.7)$ & $89(47.6)$ \\
\hline Asthma $[\mathrm{n}(\%)]$ & $27(13.4)$ & $4(28.6)$ & $23(12.3)$ \\
\hline Rhinitis [n (\%)] & $42(20.9)$ & $4(28.6)$ & $38(20.3)$ \\
\hline Contact dermatitis $[\mathrm{n}(\%)]$ & $10(5.0)$ & 0 & $10(5.3)$ \\
\hline Duration of symptoms (years) $[\mathrm{M} \pm \mathrm{SD}(\min .-\mathrm{max})]$ & $7.0 \pm 6.4(1-36)$ & $9.9 \pm 11.2(1-36)$ & $6.7 \pm 5.8(1-35)$ \\
\hline $\begin{array}{l}\text { Latency period (duration of exposure before } \\
\text { the occurrence of symptoms) (years) }[\mathrm{M} \pm \mathrm{SD} \\
\text { (min.-max)] }\end{array}$ & $13.3 \pm 8.9(1-37)$ & $10.0 \pm 9.1(1-28)$ & $13.6 \pm 8.8(1-37)$ \\
\hline
\end{tabular}

$\mathrm{M}$ - mean; SD - standard deviation; min. - minimum value; max - maximum value. CCDs - cross-reactive carbohydrate determinants. 
IgE in serum. Positive SPT results to common and occupational allergens were found in $9(64.3 \%)$ and $5(35.7 \%)$ of CCD-positive patients, respectively. Table 2 shows the detailed characteristics of the subjects with the anti-CCD $\operatorname{IgE}$ in serum.

The comparison of the reported allergy symptoms, the results of SPT to common and occupational allergens as well as the total and SIgE determinations among CCDpositive patients and those without SIgE to CCDs did not show significant differences (Table 3). At least one positive SPT response to common allergens was found in $64.3 \%$ of CCD-positive subjects and in $55.1 \%$ of those without SIgE to CCDs in serum, while sensitization to occupational allergens was detected in $35.7 \%$ and $50.8 \%$ of patients, respectively. Total IgE level was elevated in both groups and a significant percentage of subjects with more than $100 \mathrm{kU} / 1 \mathrm{IgE}$ was found, particularly among CCDpositive subjects (85.7\%). Only sensitisation to weed pollens and elevated mean total $\mathrm{IgE}$ level were more frequent in CCD-positive subjects (42.9\% and $85.7 \%$, respectively) than in those without $\operatorname{sIgE}$ to CCDs $(15.5 \%, \mathrm{p}<0.05$, and $47.6 \%, p=0.01$, respectively).

The frequency of CCD-positivity as well as the kU/l-values of anti-CCD IgE results did not vary significantly between patients with evident clinical occupational allergy and those with suspected occupational allergy (Table 4). Only the sensitisation to occupational allergens and the multisensitisation to common allergens were more frequently associated with occupational allergy.

\section{DISCUSSION}

Immunologic IgE-dependent mechanisms have been confirmed for many causes of occupational respiratory allergy, particularly for high-molecular-weight (HMW) allergens. Hence, the assessment of sensitization is an important stage in diagnosis of occupational allergy and includes skin tests and/or specific IgE measurement. However, it is pointed out that reliable interpretation of the immunologic tests

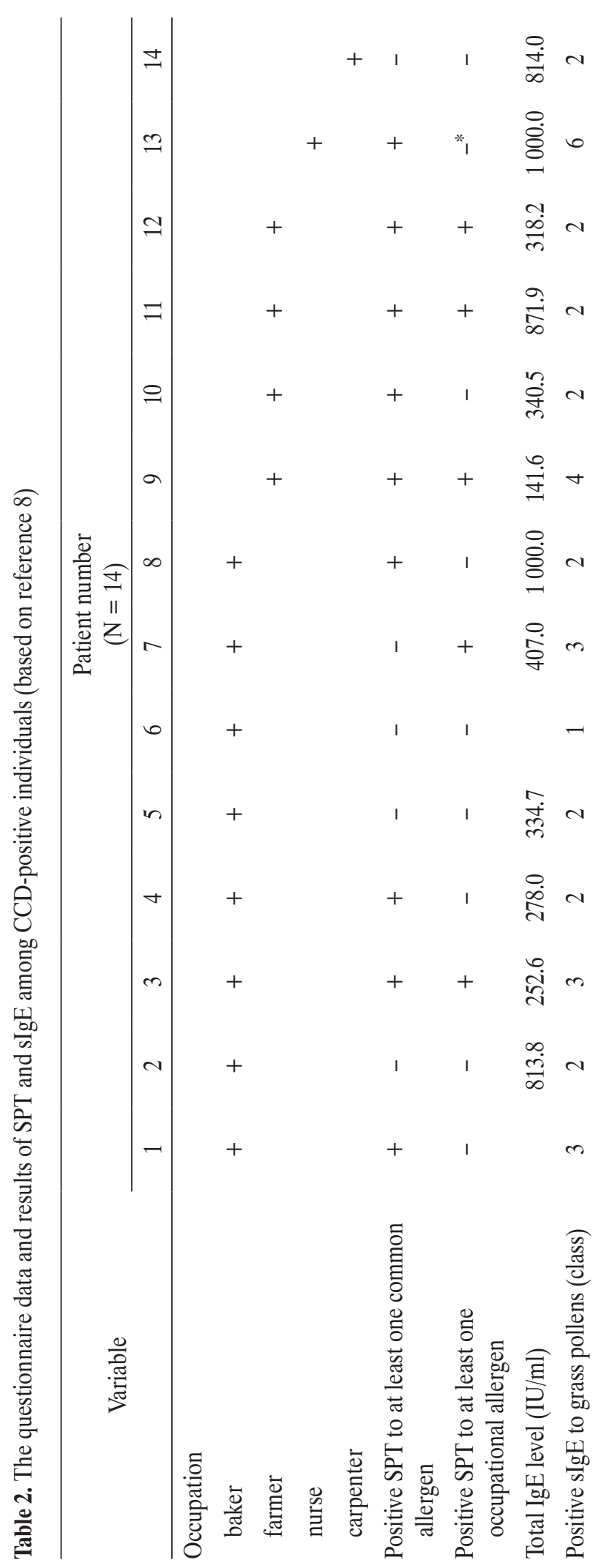




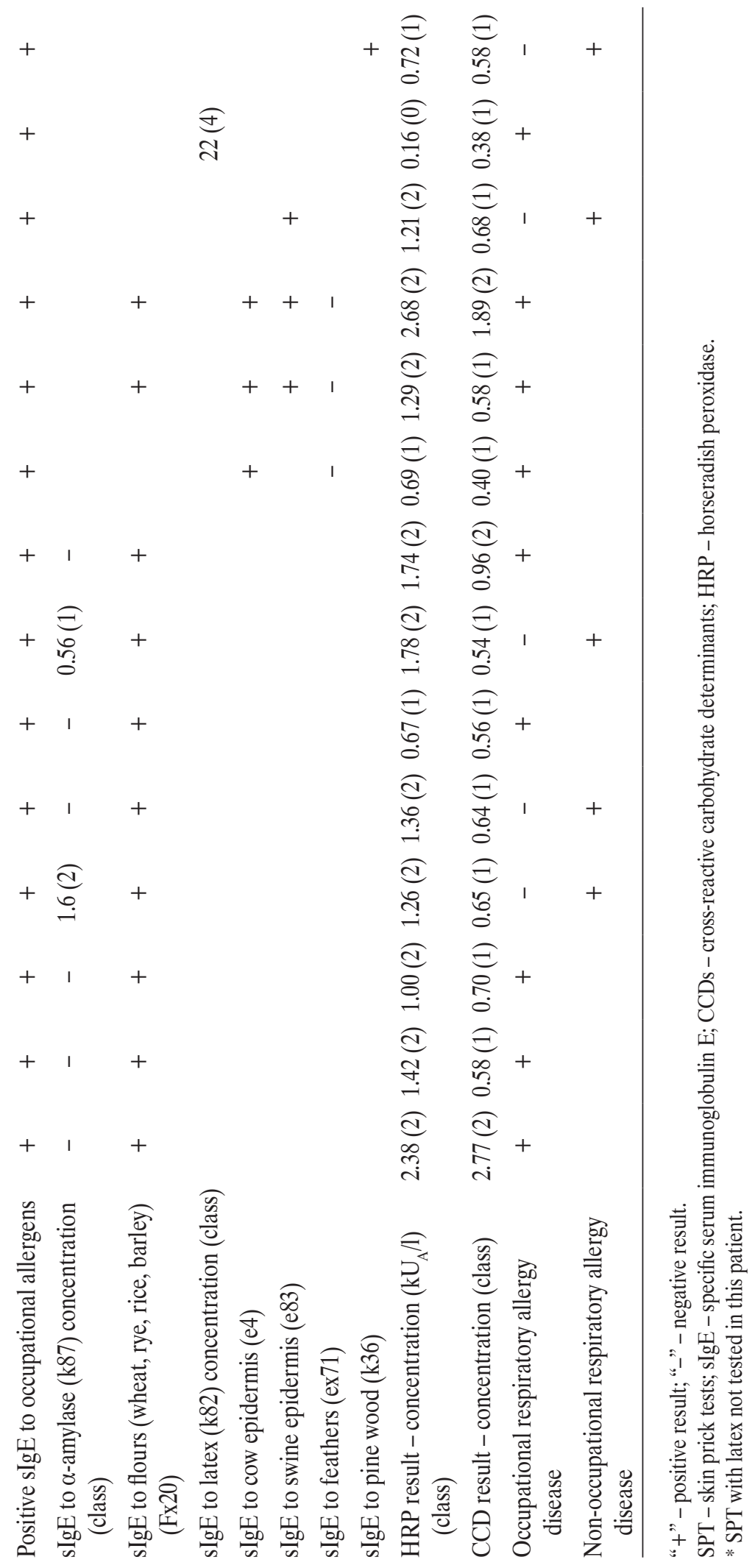


Table 3. Prevalence of reported symptoms, SPT results for common and occupational allergens and evaluation of total and specific IgE levels in study population depending on anti-CCD IgE presence

\begin{tabular}{|c|c|c|c|}
\hline Variable & $\begin{array}{c}\text { CCD-positive } \\
(\mathrm{N}=14)\end{array}$ & $\begin{array}{l}\text { CCD-negative } \\
(\mathrm{N}=187)\end{array}$ & $\mathrm{p}$ \\
\hline \multicolumn{4}{|l|}{ Questionnaire data $[\mathrm{n}(\%)]$} \\
\hline family history of atopy & $1(7.1)$ & $46(24.6)$ & n.s. \\
\hline pets at home & $4(28.6)$ & $56(30.0)$ & n.s. \\
\hline \multicolumn{4}{|l|}{ smoking status } \\
\hline current-smokers & $1(7.1)$ & $32(17.1)$ & n.s. \\
\hline ex-smokers & $7(50.0)$ & $59(31.0)$ & n.s. \\
\hline sex: male & $10(71.4)$ & $116(64.0)$ & n.s. \\
\hline \multicolumn{4}{|l|}{ Reported allergy symptoms [n (\%)] } \\
\hline cough & $9(64.3)$ & $119(63.6)$ & n.s. \\
\hline dyspnea & $13(92.9)$ & $148(79.1)$ & n.s. \\
\hline rhinitis & $14(100.0)$ & $146(78.1)$ & n.s. \\
\hline conjunctivitis & $9(64.3)$ & $81(43.3)$ & n.s. \\
\hline skin symptoms & $4(28.6)$ & $72(38.5)$ & n.s. \\
\hline \multicolumn{4}{|l|}{ Positive SPT results [n $(\%)]$} \\
\hline to at least 1 common allergen & $9(64.3)$ & $100(53.5)$ & n.s. \\
\hline mono-sensitization to common allergens & $5(35.7)$ & $61(32.6)$ & n.s. \\
\hline multiple-sensitization to common allergens & $4(28.6)$ & $39(20.9)$ & n.s. \\
\hline sensitization to 2 common allergens & $4(28.6)$ & $31(16.6)$ & n.s. \\
\hline sensitization to 3 common allergens & 0 & $6(3.2)$ & n.s. \\
\hline sensitization to 4 common allergens & 0 & $2(1.1)$ & n.s. \\
\hline feathers & $1(7.1)$ & $4(2.1)$ & n.s. \\
\hline grass pollens & $4(28.6)$ & $33(17.6)$ & n.s. \\
\hline tree pollens $\mathrm{I}^{1}$ & $3(21.4)$ & $26(13.9)$ & n.s. \\
\hline tree pollens $\mathrm{II}^{2}$ & $4(28.6)$ & $32(17.1)$ & n.s. \\
\hline moulds I* & 0 & $7(3.7)$ & n.s. \\
\hline moulds II** & 0 & $4(2.1)$ & n.s. \\
\hline Dermatophagoides pteronyssinus & $6(42.9)$ & $52(27.8)$ & n.s. \\
\hline Dermatophagoides farinae & $6(42.9)$ & $55(29.4)$ & n.s. \\
\hline weeds & $6(42.9)$ & $29(15.5)$ & $<0.05$ \\
\hline Acarus siro & $5(35.7)$ & $36(19.3)$ & n.s. \\
\hline Lepidoglyphus destructor & $5(35.7)$ & $39(20.9)$ & n.s. \\
\hline Thyrophagus putrescentiae & $5(35.7)$ & $37(19.8)$ & n.s. \\
\hline at least 1 occupational allergen & $5(35.7)$ & $95(50.8)$ & n.s. \\
\hline only common allergens & $5(35.7)$ & $43(23.0)$ & n.s. \\
\hline only occupational allergens & $1(7.1)$ & $35(18.7)$ & n.s. \\
\hline common and occupational allergens & $4(28.6)$ & $60(32.1)$ & n.s. \\
\hline
\end{tabular}


Table 3. Prevalence of reported symptoms, SPT results for common and occupational allergens and evaluation of total and specific IgE levels in study population depending on anti-CCD IgE presence - cont.

\begin{tabular}{lccc}
\hline \multicolumn{1}{c}{ Variable } & $\begin{array}{c}\text { CCD-positive } \\
(\mathrm{N}=14)\end{array}$ & $\begin{array}{c}\text { CCD-negative } \\
(\mathrm{N}=187)\end{array}$ & $\mathrm{p}$ \\
\hline Total IgE and sIgE measurements & & & \\
total IgE level $(\mathrm{kU} / \mathrm{l})[\mathrm{M} \pm \mathrm{SD}(\min .-\mathrm{max})]$ & $547.6 \pm 322.2(141-1000)$ & $190.8 \pm 214.6(6-1000)$ & n.s. \\
total $\mathrm{IgE}>100 \mathrm{kU} / \mathrm{l}[\mathrm{n}(\%)]$ & $12(85.7)$ & $89(47.6)$ & 0.01 \\
sIgE to occupational allergens $[\mathrm{n}(\%)]$ & $14(100)$ & $162(86.6)$ & n.s. \\
\hline
\end{tabular}

${ }^{1}$ Alder, hazel, poplar, elm, willow.

${ }^{2}$ Birch, beech, oak, plane.

* Alternaria tenuis, Botrytis cinerea, Cladosporium herbarum, Culvularia lunata, Helminthosporium, Fusarium moniliforme.

** Aspergillus fumigatus, Mucor mucedo, Penicillium notatum, Pullularia pullulans, Rhizopus nigricans, Serpula lacrimans.

n.s. - not statistically significant. Other abbreviations as in Tables 1 and 2.

Table 4. SPT results for common and occupational allergens and evaluation of total and specific IgE levels in subjects with occupational respiratory allergy and suspected occupational allergy

\begin{tabular}{|c|c|c|c|}
\hline Variable & $\begin{array}{c}\text { Occupational respiratory } \\
\text { allergy } \\
(\mathrm{N}=107) \\
\end{array}$ & $\begin{array}{c}\text { Suspected occupational } \\
\text { allergy } \\
(\mathrm{N}=94) \\
\end{array}$ & $\mathrm{p}$ \\
\hline \multicolumn{4}{|l|}{ Total IgE and sIgE measurements } \\
\hline CCD IgE (bromelain) $[\mathrm{n}(\%)]$ & $9(8.4)$ & $5(5.3)$ & n.s. \\
\hline CCD IgE (bromelain) (kU/l) [M \pm SD (min.-max)] & $0.08 \pm 0.36(0-2.77)$ & $0.03 \pm 0.132(0-0.68)$ & n.s. \\
\hline sIgE to occupational allergens $[\mathrm{n}(\%)]$ & $104(97.2)$ & $72(76.6)$ & $<0.0001$ \\
\hline total IgE level $(\mathrm{kU} / \mathrm{l})[\mathrm{M} \pm \mathrm{SD}(\min .-\max )]$ & $229.1 \pm 240.1(10-1000)$ & $181.6 \pm 204.9(6-1000)$ & n.s. \\
\hline total $\operatorname{IgE}>100 \mathrm{kU} / \mathrm{l}[\mathrm{n}(\%)]$ & $54(50.5)$ & $47(50)$ & n.s. \\
\hline \multicolumn{4}{|l|}{ Positive SPT results $[\mathrm{n}(\%)]$} \\
\hline to at least 1 common allergen & $64(59.8)$ & $45(47.9)$ & n.s. \\
\hline mono-sensitization to common allergens & $34(31.8)$ & $32(34.0)$ & n.s. \\
\hline multiple-sensitization to common allergens & $30(28.0)$ & $13(13.8)$ & $<0.05$ \\
\hline sensitization to 2 common allergens & $25(23.3)$ & $10(10.6)$ & $<0.05$ \\
\hline sensitization to 3 common allergens & $4(3.7)$ & $2(2.1)$ & n.s. \\
\hline sensitization to 4 common allergens & $1(0.9)$ & $1(1.1)$ & n.s. \\
\hline to at least 1 occupational allergen & $72(67.3)$ & $28(29.8)$ & $<0.0001$ \\
\hline
\end{tabular}

Abbreviations as in Tables 1-3.

used in the diagnosis of occupational allergy requires validation, mainly based on the result of SICT [9].

Generally, the results of the immunologic tests can indicate exposure and sensitization, but by themselves are unable to confirm a diagnosis of occupational asthma. Beach et al. estimated the sensitivity and specificity for sIgE to HMW agents to be $73.3 \%$ and $79 \%$, respectively [10]. There are several mechanisms resulting in clinically irrelevant sIgE, 
e.g., nonspecific absorption frequently associated with high total serum IgE levels, and cross-reactivity due to panallergens and CCDs [1,11,12].

In addition, serological tests may not be as sensitive as SPT [13] and it is likely that the discrepancies between negative skin test responses and positive sIgE detection can be associated with the presence of sIgE to CCDs [14]. To examine if the presence of $\operatorname{sgE}$ to CCDs in serum might affect results of the determinations of sIgE to occupational allergens, we assessed the frequency of positive response to CCDs in the subjects with suspected occupational allergy and its relation to the results of other diagnostic tests and final diagnosis.

In our paper, we used the radioallergosorbent test for bromelain in all subjects and finally HRP to obtain information on the presence of $\mathrm{IgE}$ against the glycan groups. The bromelain is the glycoprotein most widely used to identify $\operatorname{IgE}$ reactivity to CCDs and the positive result for a bromelain-specific IgE test indicates either the presence of anti-CCD IgE in the patient's serum or, less likely, that the subjects could be sensitized to bromelain [15]. In contrast, HRP is a polyvalent plant glycoprotein. However, both HRP and MUXF3 CCD ImmunoCAP were evaluated as a valuable screening allergen for the detection of CCD-sIgE [16].

In Altmann review, it has been estimated that over $20 \%$ of allergic patients have IgE that binds to carbohydrate compounds [5]. The anti-CCD IgE was found among $28 \%$ of patients allergic to bee venom [17], whereas in Kochuyt et al. study the 'CCD positivity' was observed in $47 \%$ of subjects with honeybee and yellow jacket venom allergy [18]. The highest prevalence of the anti-CCD IgE to bromelain (45-55\%) was observed in studies of carrot and celery allergens $[19,20]$.

Only few data are accessible on the prevalence of antiCCD IgE among patients suspected to suffer from occupational allergy. In Sander et al. study [21] sIgE to any CCDs (bromelain and HRP) was measured in $30 \%$ of the bakers with work-related asthma/rhinitis, compared to $80 \%$ of the controls with pollinosis. In Kespohl et al. study, woodworkers sensitized to beech and pine allergens showed a high prevalence of CCD sensitization (73\%); however, workers with a single sensitization to wood had no $\operatorname{sgE}$ to CCDs [22]. In our study, sIgE to CCDs was found in $7 \%$ of subjects with suspected occupational respiratory allergy disease, mainly among farmers (11.4\%). Lower prevalence of IgE sensitization to CCDs has been observed among beekeepers $(2.6 \%)$ [23].

It is pointed out that the recognition of anti-CCD $\operatorname{IgE}$ might be related to the 'atopic' status [18]. Similarly to previous studies, in our study sIgE to grass pollen was also detected in all CCD-positive subjects, although only 4 of them had positive response to grass pollen allergens in SPT [21]. Mari suggested a role for CCD IgE as a marker of the risk of developing multiple allergies [15]. In the present study, a significant correlation was found between the presence of CCDs in serum and sensitisation to weed pollens, although we did not confirm the relationship between the mono- or multiple sensitisation to common allergens and presence of CCD SIgE in serum. Also Kespohl et al. did not find correlation between positive results of $\operatorname{sIgE}$ to the most common inhalative allergens and CCDs [22]. Other results demonstrated that in CCDpositive patients with suspected respiratory allergy, male sex and atopy were associated with CCD sensitization and this sensitization was more frequent in pollen-sensitized patients than in those sensitized to mites [24]. In Vidal et al. study, CCD sensitization was not significantly associated with age, rural residence, alcohol consumption or smoking [24]. On the other hand, among beekeepers, the presence of anti-CCD IgE was positively associated with atopy and higher levels of serum total $\operatorname{IgE}$ [23].

In our study, in the majority of CCD-positive subjects, the average total $\mathrm{IgE}$ level was elevated, additionally in 2 subjects it was above $1000 \mathrm{kU} / \mathrm{l}$. Moreover, a significant correlation was found to occur between the total $\operatorname{IgE}$ 
level over $100 \mathrm{kU} / \mathrm{l}$ and presence of the sIgE to CCDs. This could be explained by the fact that nonspecific absorption, frequently associated with high total serum $\operatorname{IgE}$, might be responsible for the presence of clinically irrelevant sIgE. On the other hand, the possible effect of high total IgE levels on the detection of CCD IgE has been ruled out in the Mari study [15].

It has been proved that the presence of CCD IgE directly correlates with positive assay for many different allergenic extracts that are unable to trigger an allergic reaction in the skin test [15]. In our study, the sIgE to occupational allergens were detected in all CCD-positive patients, while positive SPT to occupational allergens were found in 5 of those subjects. Additionally, in one nurse, the SPT to latex could probably have been positive (as she reported in history an urticarial reaction associated with wearing latex gloves at work) but it was not confirmed due to the contraindication for prick testing with latex allergens. Finally, in 9 of CCD-positive patients, the occupational asthma and/or rhinitis were recognized from the result of SICT.

In Sander et al. study [21], IgE results to HRP and bromelain were significantly correlated. Unexpectedly, in our study, negative HRP result was found in 1 CCD-positive subject, although high level of sIgE and positive SPT to grass pollens were found in that patient. The reason why the sIgE to HRP was negative is uncertain at this moment. The clinical significance of sIgE to CCDs in occupational allergy remains unclear. Unlike results of other authors, in our study all the CCD-positive patients reported workrelated respiratory symptoms; moreover, occupational allergy disease was recognised in $64.3 \%$, and work-exacerbated asthma or rhinitis in $(35.7 \%)$ of those patients. In Ebo et al. study, CCDs of natural rubber latex allergens were confirmed to mimic latex sensitization [11]. In our study, presence of anti-CCD IgE should be excluded as the reason for cross-reaction to both common and occupational allergens, because non-occupational respiratory allergy was recognized only in 5 patients with positive sIgE to CCDs. In patients with occupational asthma, concomitant sensitizations to occupational allergens seemed to be an independent phenomenon (co-sensitization) proved by positive SICT results.

The results of our study revealed that sIgE to occupational allergens found in sera of CCD-positive patients could not be considered as 'irrelevant' results caused by cross-reactive mechanism. Recognition of occupational respiratory allergy was based on SICT results, therefore the presence of sIgE to occupational allergens confirmed occupational origin of the disease even if the patients did not react to workplace allergens in the skin prick testing. In the unclear cases, the relevance of sIgE could be proved by using properly folded recombinant allergens.

A limitation of our study is a lack of determination of HRP in all subjects. Detection of anti-HRP or anti-bromelain IgE by UniCAP is a practical tool for the detection of anti-CCD IgE [25]. However, it has been pointed out that the HRP contains $6 \mathrm{~N}$-linked glycans, while bromelain carries only 1 carbohydrate chain. Therefore, some authors emphasize that bromelain is an imperfect CCD model [26]. Furthermore, the RAST inhibition test using HRP as an inhibitor was not performed in the present study, while the pre-incubation of the sera with HRP could abrogate IgE binding to occupational allergens.

It was suggested that anti-CCD IgE detection should be implemented in allergy diagnostic process to prevent misdiagnosis, but considering our study results, it is not useful method in occupational allergy. Similarly to our results, also Kochuyt et al. have concluded that positive bromelain CAP test does not exclude clinical reactivity to venoms in allergic patients [18].

\section{CONCLUSIONS}

In conclusion, specific IgE to CCDs can be found in $7 \%$ of subjects suspected to suffer from occupational respiratory allergy disease. The presence of anti-CCD IgE in serum is not significantly associated with occupational respiratory 
allergy. Additionally it is also not more frequent among subjects reporting work-related respiratory symptoms in whom occupational allergy was not confirmed. The elevated total IgE level is related with CCD-positivity in subjects with suspected occupational allergy.

\section{REFERENCES}

1. Staple S, Kleine-Tebbe J. Allergy testing in laboratory. In: Kay A, Kaplan A, Bousquet J, Holt P, editors. Allergy and allergic diseases. 2nd ed. Oxford: Wiley-Blackwell; 2008. p. 1346-67.

2. Malandain H, Giroux F, Cano Y. The influence of carbohydrate structures present in common allergen sources on specific $\operatorname{IgE}$ results. Eur Ann Allergy Clin Immunol. 2007;39:216-20.

3. Aalberse RC, Koshte VL, Clemens JGJ. Immunoglobulin E antibodies that cross-react with vegetable foods, pollen and Hymenoptera venom. J Allergy Clin Immunol. 1981;68:356, http://dx.doi.org/10.1016/0091-6749(81)90133-0.

4. Aalberse RC, Koshte VL, Clemens JGJ. Cross-reactions between vegetable foods, pollen and bee venom due to $\operatorname{IgE}$ antibodies to a ubiquitous carbohydrate determinant. Int Arch Allergy Appl Immunol. 1981;66:259, http://dx.doi. org/10.1159/000232913.

5. Altmann F. The role of protein glycosylation in allergy. Int Arch Allergy Immunol. 2007;142:99-115, http://dx.doi. org/10.1159/000096114.

6. van der Veen MJ, van Ree R, Aalberse RC, Akkerdaas J, Koppelman SJ, Jansen HM, et al. Poor biologic activity of cross-reactive $\mathrm{IgE}$ directed to carbohydrate determinants of glycoproteins. J Allergy Clin Immunol. 1997;100:327-34, http://dx.doi.org/10.1016/S0091-6749(97)70245-8.

7. Mari A, Ooievaar-de Heer P, Scala E, Giani M, Pirritta L, Zuidmeer L, et al. Evaluation by double-blind placebo-controlled oral challenge of the clinical relevance of $\operatorname{IgE}$ antibodies against plant glycans. Allergy. 2008;63:891-6, http://dx.doi. org/10.1111/j.1398-9995.2008.01703.x.

8. Wiszniewska M, Zgorzelska-Kowalik J, Nowakowska-Świrta E, Pałczyński C, Walusiak-Skorupa J. Cross-reactive carbohydrate determinants in diagnostics of occupational allergy - preliminary results. Allergy. 2010;65:664-6, http:/ dx.doi.org/10.1111/j.1398-9995.2009.02219.x.

9. Bernstein J. Occupational asthma. In: Mahmoudi M, editor. Allergy and asthma: Practical diagnosis and management. New York: McGraw-Hill Medical; 2007. p. 145-55.

10. Beach J, Russell K, Blitz S, Hooton N, Spooner C, Lemiere C, et al. A systematic review of the diagnosis of occupational asthma. Chest. 2007;131:569-78, http://dx.doi.org/10.1378/ chest.06-0492.

11. Ebo DG, Lechkar B, Schuerwegh AJ, Bridts CH, de Clerck LS, Stevens WJ. Validation of a two-color flow cytometric assay detecting in vitro basophil activation for the diagnosis of IgE-mediated natural rubber latex allergy. Allergy. 2002;57:706-12, http://dx.doi.org/10.1034/j.1398-99 95.2002.23553.x.

12. Malandain H. Widening sensitization spectrum through carbohydrate panepitopes - A hypothesis. Eur Ann Allergy Clin Immunol. 2004;36:297-9.

13. Nicholson PJ, Cullinan P, Taylor AJ, Burge PS, Boyle C. Evidence based guidelines for the prevention, identification, and management of occupational asthma. Occup Environ Med. 2005;62:290-9, http://dx.doi.org/10.1136/ oem.2004.016287.

14. Mari A, Iacovacci P, Afferni C, Barletta B, Tinghino R, di Felice G, et al. Specific IgE to cross-reactive carbohydrate determinants strongly affect the in vitro diagnosis of allergic diseases. J Allergy Clin Immunol. 1999;103:1005-11, http:// dx.doi.org/10.1016/S0091-6749(99)70171-5.

15. Mari A. IgE to cross-reactive carbohydrate determinants: Analysis of the distribution and appraisal of the in vivo and in vitro reactivity. Int Arch Allergy Immunol. 2002;129: 286-95, http://dx.doi.org/10.1159/000067591.

16. Jappe U, Raulf-Heimsoth M, Hoffmann M, Burow G, Hübsch-Müller C, Enk A. In vitro hymenoptera venom allergy diagnosis: Improved by screening for cross-reactive carbohydrate determinants and reciprocal inhibition. Allergy. 2006;61:1220-9, http://dx.doi.org/10.1111/j.1398-9995. 2006.01232.x. 
17. Tretter V, Altmann F, Kubelka V, Marz L, Becker WM. Fucose alpha 1,3-linked to the core region of glycoprotein $\mathrm{N}$-glycans creates an important epitope for IgE from honeybee venom allergic individuals. Int Arch Allergy Immunol. 1993;102:259-66, http://dx.doi.org/10.1159/000236534.

18. Kochuyt AM, van Hoeyveld EM, Stevens EA. Prevalence and clinical relevance of specific immunoglobulin E to pollen caused by sting-induced specific immunoglobulin $\mathrm{E}$ to cross-reacting carbohydrate determinants in Hymenoptera venoms. Clin Exp Allergy. 2005;35:441-7, http://dx.doi. org/10.1111/j.1365-2222.2005.02217.x.

19. Ballmer-Weber BK, Wuthrich B, Wangorsch A, Fotisch K, Altmann F, Vieths S. Carrot allergy: Double-blinded, placebo-controlled food challenge and identification of allergens. J Allergy Clin Immunol. 2001;108:301-7, http://dx.doi. org/10.1067/mai.2001.116430.

20. Luttkopf D, Ballmer-Weber BK, Wuthrich B, Vieths S. Celery allergens in patients with positive double-blind placebo-controlled food challenge. J Allergy Clin Immunol. 2000;106: 390-9, http://dx.doi.org/10.1067/mai.2000.108711.

21. Sander I, Rozynek P, Rihs HP, van Kampen V, Chew FT, Lee WS, et al. Multiple wheat flour allergens and crossreactive carbohydrate determinants bind IgE in baker's asthma. Allergy. 2011;66:1208-15, http://dx.doi.org/10.1111/ j.1398-9995.2011.02636.x.
22. Kespohl S, Schlunssen V, Jacobsen G, Schaumburg I, Maryska S, Meurer U, et al. Impact of cross-reactive carbohydrate determinants on wood dust sensitization. Clin Exp Allergy. 2010;40:1099-106, http://dx.doi.org/10.1111/j.13652222.2010.03514.x.

23. Carballada FJ, Gonzalez-Quintela A, Nuñez R, Vidal C, Boquete M. Low prevalence of IgE to cross-reactive carbohydrate determinants in beekeepers. J Allergy Clin Immunol. 2011;128:1350-2, http://dx.doi.org/10.1016/j.jaci. 2011.08.002.

24. Vidal C, Sanmartín C, Armisén M, Rodríguez V, Linneberg A, Gonzalez-Quintela A. Minor interference of cross-reactive carbohydrates with the diagnosis of respiratory allergy in standard clinical conditions. Int Arch Allergy Immunol. 2012;157:176-85, http://dx.doi. org/10.1159/000324447.

25. Ito K, Morishita M, Ohshima M, Sakamoto T, Tanaka A. Cross-reactive carbohydrate determinant contributes to the false positive IgE antibody to peanut. Allergol Int. 2005;54:387-92, http://dx.doi.org/10.2332/allergolint.54.387.

26. Malandain H. IgE-reactive carbohydrate epitopes - Classification, cross-reactivity, and clinical impact (2nd part). Eur Ann Allergy Clin Immunol. 2005;37:247-56.

This work is available in Open Access model and licensed under a Creative Commons Attribution-NonCommercial 3.0 Poland License - http://creativecommons.org/ licenses/by-nc/3.0/pl/deed.en. 